\title{
TUTELA DE URGÊNCIA CONTRA O PODER PÚBLICO
}

\section{PRELIMINARY OR PROVISORY INJUNCTION AGAINST PUBLIC ADMINISTRATION}

Marcelo Lima Guerra"

\begin{abstract}
Resumo: O presente trabalho é voltado à análise das normas restritivas à concessão de tutela de urgência contra o Poder Público, na perspectiva da teoria dos direitos fundamentais e do modelo constitucional de processo, bem como de recente decisão do Supremo Tribunal Federal sobre a matéria.

Palavras-chave: Tutela de Urgência. Poder Público. Restrições legais. Proporcionalidade. Constitucionalidade.

Abstract: The present paper is directed toward na analysis of legal norms imposing restrictions on granting a preliminary or provisory injunction against Public Administration, under the perspective of the constitutional rights theory and the constitutional model for judicial process, as well as to the analysis of a recent decision from brazilian Suprem Court on the issue.
\end{abstract}

Keywords: Preliminary and provisory injunctions. Public Administration. Legal restrictions. Proportionality. Constitutionality.

\section{INTRODUÇÃO}

É amplamente sabido que, no direito brasileiro há várias normas estabelecendo óbices ou vedações à concessão de providências urgentes antecipatórias contra o Poder Púbico em determinados grupos de situação. $\mathrm{O}$ tema tem sido matéria de acirradas disputas, tendo mesmo sido levada, através da Ação Declaratória de Costitucionalidade n. 4, à apreciação do Supremo Tribunal Federal. ${ }^{1}$

Mestre e Doutor em Direito pela PUC-SP. Professor da Graduação e do Curso de Mestrado da Faculdade de Direito da Universidade Federal do Ceará. Juiz do Trabalho Substituto do TRT-7 ${ }^{a}$ Região.

${ }^{1}$ Sobre o tema, a bibliografia é já vastíssima. Exemplificativamente, cf.: Benucci (2001); Bueno (2004; 2000); Bueno e Sundfeld (2000); Dantas (1999); Federighi (1996); Frias (1996); Guerra (2003); Greco Filho (1986); Rocha Sobrinho (1999); Shimura e Alvim Wambier (2001); Silva (1996); Silva (1999); Souza (2000); Venturi (2005); Viana (2003, 1998); Vilela (1998); Wambier (1997); Alvim Wambier (1997). 
Tais restrições se revelam como limitações ao controle jurisdicional do Poder Público, bem como à realização (entre outros) do valor constitucional consistente na efetividade da tutela jurisdicional, entendida como máxima coincidência possível. ${ }^{2}$ Urge, portanto, avaliar tais restrições à luz do modelo constitucional de processo, bem como das noções básicas que integram a teoria dos direitos fundamentais, a fim de se aferir a sua compatibilidade ou não com a ordem constitucional brasileira. Este é o objetivo do presente trabalho, o qual também analisará a decisão já proferida sobre o assunto, embora sob a forma de medida liminar, pelo próprio STF.

Antes, porém, de passar ao tratamento do tema, impõe-se fixar alguns pontos prelimimares. A expressão 'tutela de urgência' designará, no presente trabalho, uma categoria de providência jurisdicional identificada com base em critério puramente funcional: integram a categoria da tutela de urgência exclusivamente as providências jurisdicionais voltadas à eliminação do periculum in mora, sendo irrelevante a técnica utilizada para tanto (antecipação de resultados ou conservação de situação de fato), bem como qualquer outro aspecto da disciplina normativa de tais medidas - relacionado aos seus requisitos, aos aspectos procedimentais (sobretudo quanto ao momento em que é concedida) etc.

Este conceito funcional de tutela de urgência é tal que o torna não inteiramente coincidente com o de tutela antecipada: há providências que pertencem à categoria da tutela de urgência, construída assim funcionalmente, que não pertencem à categoria da tutela antecipada, tais como as providências (agora denominadas pela doutrina predominante como "tipicamente" cautelares, aqui denominadas) urgentes conservatórias, e.g. arresto e sequestro; há providências antecipatórias que não integram a categoria da tutela de urgência, por serem desprovidas do elemento funcional característico, ou seja, a finalidade específica de eliminar

2 Sobre os vários sentidos que a expressão 'efetividade da tutela jurisdicional' (bem como a congênere 'efetividade do processo') foi adquirindo, nas últimas décadas, com o surgimento de uma grande variedade de expressões sinônimas, cf. Guerra (1998, p. 48-9, 54-6). Aqui, adota-se a expressão 'máxima coincidência possível', cunhada por Barbosa Moreira (cf. BARBOSA MOREIRA, 1989, p. 215 et seq.) para se referir à exigência específica, integrante do vasto conteúdo coberto pelo direito à tutela efetiva, de que o resultado concreto obtido através do processo corresponda o máximo possível, ao que dele se é de esperar obter, à luz do ordenamento jurídico - exigência esta captada, com clareza ímpar, na famosa fórmula chiovendiana, segundo a qual "o processo deve dar a quem tem um direito, na medida do praticamente possível, tudo aquilo e exatamente aquilo que ele tem direito a obter". 
determinado periculum in mora (e.g. a antecipação de tutela prevista no inc. II do Art. 273 do CPC). ${ }^{3}$

A principal justificativa desta distinção entre tutela de urgência e tutela antecipada é que a tutela de urgência reúne providências que devem ser submetidas a um regime comum, pois a finalidade específica atribuída a elas assim o impõe, na medida em que tal finalidade se traduz na concretização de um direito fundamental. O mesmo não ocorrendo com a tutela antecipada, a qual se chega a ter alguma relevância, na perspectiva da realização de algum direito fundamental, não o tem de modo necessário e tão evidente como é o caso de toda e qualquer medida voltada à eliminação de um periculum in mora concreto.

O presente texto não comporta maiores digressões sobre estes pontos. Eles não poderiam, todavia, deixar de ser mencionados para bem delimitar o alcance dos argumentos aqui traçados. Com efeito, nada do que se diz sobre a tutela de urgência contra o Poder Público, no presente escrito, aplica-se às providências antecipatórias não voltadas à eliminaçào do periculum in mora, entre elas, aquela prevista no Art. 273, II, do CPC.

\section{LIMITES À TUTELA DE URGÊNCIA CONTRA O PODER PÚBLICO DECORRENTES DOS LIMITES AO CONTROLE JURISDICIONAL DOS ATOS ADMINISTRATIVOS}

Ao enfrentar o tema da tutela de urgência contra o Poder Público, é indispensável determinar, preliminarmente, a extensão do controle jurisdicional a que ele, o Poder Público, se submete, para verificar se daí decorre alguma limitação ao uso de tais providências. O princípio da separação dos poderes tanto se realiza pela reserva ao Poder Público de uma área de atuação isenta de controle jurisdicional - a discricionariedade administrativa ${ }^{4}$ - como também,

${ }^{3}$ Cf. Guerra (1997, passim); Bedaque (2001, p. 321 et seq.).

${ }^{4}$ Nesta oportunidade, vale um registro, por superficial que seja, sob a discricionariedade administrativa, vista sob a perspectiva da teoria da norma jurídica. $\mathrm{O}$ fenômeno que vem sendo estudado sob a epígrafe de 'discricionariedade administrativa' não é exclusivo da Administração Pública - o que já foi percebido com relação à atuação do legislador e do magistrado - mas também não é exclusivo da atuação dos Poderes Públicos, verificando-se, igualmente, no âmbito privado. Isso é o que se conclui, quando se adota, como perspectiva, aquela oferecida pelas normas de competência. Normas de competência conferem a determinados sujeitos a possibilidade (poder) de alterar posições normativas de outros sujeitos (e também de bens e condutas). Essa possibilidade hipotética ou poder conferido por uma norma de competência é a mesma, seja o 
ao mesmo tempo, pela submissão total da atuação do mesmo Poder Público, naquilo que ultrapassa àquela área, ao controle jurisdicional. ${ }^{5}$ Dessa forma, ultrapassado o limite (cada vez mais estreito) da discricionariedade, a submissão do Poder Público ao controle jurisdicional - em todas as dimensões da atuação jurisdicional, e com relação a qualquer das técnicas processuais - é total. No que diz com o uso das tutelas de urgência, isso significa que não há (não deve haver), em princípio, nenhuma limitação à emissão de qualquer providência urgente contra o Poder Público, desde que, obviamente, a própria tutela jurisdicional pretendida pela parte (privada), cuja prestação integral se procura assegurar por tais providências urgentes, seja possível, na perspectiva da discricionariedade. Este, portanto, o único limite lícito que, na perspectiva da discricionariedade e dos limites que ela impõe ao controle jurisdicional dos atos adminsitrativos, se pode estabelecer ao uso de tutela de urgência contra o Poder Público. Seja advertido que este limite nada mais é do que um corolário da natureza instrumental das providências jurisdicionais urgentes, com relação a outras modalidades de tutela jurisdicional.

\section{AS NORMAS VEICULADAS PELO ART. 471, I, DO CPC E PELO ART. 100 DA CF NÃO CONSTITUEM ÓBICES LEGAIS À CONCESSÃO DE TUTELA DE URGÊNCIA CONTRA O PODER PÚBLICO}

Nesta ordem, cumpre afastar, desde logo, a idéia de que normas como a que impõe o reexame necessário, bem como aquela que impõe o precatório para a tutela executiva de obrigações pecuniárias contra a Fazenda Pública constituam óbices legais à emissão de providências urgentes, mesmo de cunho pecuniário e antecipatório, contra o Poder Público. O argumento principal é que submeter a concessão de providências antecipatórias urgentes às normas do Art. 471, I, do CPC e do Art. 100 da CF significa, virtualmente, negar a própria possibilidade de tutela de urgência contra o Poder Público. É que ambas as regras se revelam

sujeito a quem se atribui a competência uma pessoa jurídica de direito público ou um sujeito privado. Sempre que a competência atribuída por uma norma respectiva puder ser exercida, numa situação concreta, através de mais de um ato e não for possível determinar, racionalmente, qual dos atos é o mais correto, à luz do ordenamento jurídico, o controle jurisdicional ou não poderá dirigir-se a essa escolha, ou ficará restrito a anular uma das opções possíveis. Sobre o conceito de competência legal (equivalente à expressão inglesa "legal power", cf. por todos, Spaak (1994).

${ }^{5}$ Sobre isso, especificamente quanto à atuação in executivis em face do Poder Público, cf. Guerra (2003, p. 178-222). 
incompatíveis com a natureza urgente daquelas providências, de modo que se revela intrinsecamente contraditório admitir a tutela de urgência contra o Poder Público e sustentar a aplicação de tais regras. É como afirmar para alguém com pés e mãos atadas, que ele é livre para movimentar pés e mãos, desde que o faça sem soltar as amarras.

A esse argumento principal, é possível acrescentar outros que conjugam posições acerca da tutela antecipada com o teor literal dos textos legislativos antes mencionados (Art. 475 do CPC e Art. 100 da CF). Com efeito, é possível considerar que a providência urgente consiste, sempre, em decisão interlocutória, mesmo quando, sem muito rigor técnico, venha emitida no mesmo papel em que o é a sentença. $O$ argumento principal para tal conclusão é a noção de sentença em sentido substancial. Sentença em sentido substancial é o ato do juiz que tenha por conteúdo uma das hipóteses dos Arts. 267 ou 269 do CPC. ${ }^{6}$ A providência urgente, em nenhuma hipótese, poderá ter como conteúdo qualquer das hipóteses dos Arts. 267 ou 269 do CPC, em razão do que não pode ser considerada como sentença em sentido substancial. ${ }^{7}$

Por outro lado, não há como negar que, de um ponto de vista puramente empírico, a atuação prática das providências urgentes, especialmente as antecipatórias, apresentam, sim, uma identidade (insista-se: meramente empírica) com a tutela executiva, mas se distinguem radicalmente na perspectiva do valor jurídico. Daí porque não pode ser considerada, juridicamente, como "execução". Afastado, assim, o suposto óbice do Art. 100 da CF.

${ }^{6}$ Esta a lição exata, como sempre de Teresa Alvim Wambier: É, portanto, o conteúdo do ato sentencial que o distingue dos demais pronunciamentos judiciais e não o efeito que, como regra geral, gera, pois o gera exata e precisamente porque é sentença, porque tem o conteúdo de sentença. Os conteúdos específicos das sentenças (Arts. 267 e 269 do CPC são, assim, o critério que as distingue das decisões interlocutórias”. (ALVIM WAMBIER, 2006, p. 109). Recentemente, como se sabe, este entendimento da mestra paulistana-curitibana, foi convertido em lei, com a nova redação dada ao $\S 1^{\circ}$ do Art. 162 do CPC, verbis: "Sentença é o ato do juiz que implica alguma das situações previstas nos Arts. 267 e 269 desta lei”.

7 É razoável considerar que boa parte da importância prática em discutir-se quer a possibilidade de se conceder a antecipação de tutela "junto" da sentença (o que, insistase, não pode deixar de ser conceitualmente caracterizado como o proferimento de duas decisões, uma substancialmente interlocutória, outra substancialmente sentença, no mesmo instrumento tido, equivocadamente, como a própria sentença), quer a qualificação da decisão que aí se concede a tutela, pelo menos no que diz com a questão relativa ao recurso cabível (agravo ou apelação), parece ter sido esvaziada com 
Registre-se, por oportuno, que tais conclusões, por reforçarem a própria eficácia das providências urgentes, no sentido de servirem para afastar aquilo que, sem tais conclusões, traduzir-se-iam em óbices à concessão de tutela urgente, servem como argumentos conseqüencialistas para justificar tanto as idéias plasmadas nessas mesmas conclusões, como aquelas que lhes serviram de premissas. ${ }^{8}$ Dito de outra forma, uma razão a mais para se considerar a tutela de urgência como concedida sempre através de decisão interlocutória e como distinta da tutela executiva, seria o resultado benéfico que tais idéias produziriam no campo da tutela de urgência contra o Poder Público, permitindo afastar a incidência de normas que, se aplicadas nesse campo, implicariam uma vedação radical do uso de providências urgentes contra o Poder Público. Justificam-se as premissas, portanto, pelas conseqüências benéficas das conclusões.

\section{ADMISSIBILIDADE IN ABSTRACTO DA EXISTÊNCIA DE LIMITAÇÕES LEGAIS À CONCESSÃO DE PROVIDÊNCIAS URGENTES, INCLUSIVE CONTRA O PODER PÚBLICO}

A imposição de limites à concessão de providências urgentes não é em si incompatível com o modelo constitucional do processo. É que a própria existência de tais providências, no ordenamento jurídico brasileiro, resulta da necessidade de se buscar solucionar, através delas, um conflito entre valores fundamentais integrantes do próprio modelo constitucional do processo - conflito esse que, muitas vezes, agrava-se por envolver diversos e não apenas dois valores constitucionais em rota de colisão.

Com efeito, as providências urgentes visam a assegurar a realização do valor constitucional da máxima coincidência possível, quando ameaçado pela duração do processo - inclusive aquela "fisiológica", que é um "efeito colateral" da obediência a normas processuais que realizam outros valores integrantes do modelo

a nova redação dada ao Art. 588 do CPC. Nesse sentido, cf. Alvim Wambier (2006, p. 602-3). No entanto - e eis um dos aspectos mais fascinantes da dinâmica do ordenamento jurídico - a distinção continua relevante no contexto específico da situação tratada no texto.

${ }^{8}$ Não é mais novidade a relevância do uso dos chamados argumentos conseqüencialistas na fundamentação racional de decisões judiciais. Tais argumentos consistem em apontar as diferentes conseqüências da adoção de opiniões em conflito, sustentando como correta aquela cujas conseqüências são melhores. Sobre o papel dos argumentos conseqüencialistas no direito, é de referência obrigatória a obra de MaCcormick (1978, p. 129-51). 
constitucional do processo, sobretudo o contraditório. Assim, em assegurando a máxima coincidência, as providências urgentes sempre trazem alguma limitação a algum desses outros valores. Por isso mesmo é que o uso de providências urgentes está inevitavelmente sujeito a limitações, em decorrência de eventual preponderância que um desses valores pode apresentar, com relação àquele da máxima coincidência. Dessa forma, pode ocorrer que, mesmo diante de comprovada necessidade de providência urgente, estando presentes seus requisitos (sobretudo o periculum in mora), ela não deva ser concedida, por assim o exigirem outros valores fundamentais em jogo, além daquela da máxima coincidência.

Todavia, justamente pela natureza peculiar com que se estabelece uma colisão entre valores constitucionais, o respectivo modo de solução entre tal conflito também apresenta suas peculiaridades. Com efeito, a solução de conflito entre valores constitucionais sempre se traduz na imposição de uma restrição (às vezes total) a algum dos valores em conflito, quando não a ambos, e é marcada pela sua radical e inafastável dependência das circunstâncias do caso concreto.

\section{TOTAL INADMISSIBILIDADE, À LUZ DA NATUREZA DAS NORMAS JUSFUNDAMENTAIS QUE POSITIVAM VALORES, DE SE IMPOR SOLUÇÕES IN ABSTRACTO PARA A COLISÃO DE VALORES CONSTITUCIONAIS}

Como já fartamente documentado na doutrina, a solução de colisão entre valores constitucionais jamais pode ser obtida com a exclusão de um dos valores em conflito do ordenamento, em razão do que implica, sempre, a determinação de qual valor há de ser considerado preponderante, no caso concreto, não sendo possível generalizar tal solução para todos os casos em que tais valores se revelem em conflito. Em primeiro lugar, porque na esmagadora maioria dos casos, os valores constitucionais em conflito gozam da mesma hierarquia ou peso abstrato, precisamente por serem constitucionais. Sendo assim, generalizar uma solução pontual de conflito entre eles significaria estabelecer uma hierarquia indevida.

Em segundo lugar, mesmo naqueles raros em que se possa reconhecer uma hierarquia in abstracto entre os valores constitucionais, segundo a qual alguns seriam mais preponderantes do que outros, no caso de desses "super-valores" entrar em conflito com outro de hierarquia (constitucional) mais baixa, circunstâncias do casos concreto podem reverter essa preponderância no plano abstrato, caracterizando como preponderante, naquele caso específico e à luz de circunstâncias determinadas, o valor de menor hierarquia. Essa, aliás, é uma das mais relevantes contribuições de Alexy. ${ }^{9}$

Imagine-se, por exemplo, que numa determinada situação entram em conflito 
o valor da proteção à vida humana com o valor da proteção à propriedade privada e que se concorde que, mesmo no plano abstrato (vale dizer, com abstração de circunstâncias concretas), o primeiro é mais relevante que o segundo. O conflito em tela se caracteriza como um dilema entre realizar ou não determinada conduta, ou seja, entre realizar a conduta $\mathrm{C}$ ou optar pela sua omissão, vale dizer, realizar a conduta omissiva $\sim \mathrm{C}^{10}$ Mais precisamente, $\mathrm{C}$, em sendo cumprida, concretiza o valor da proteção à liberdade e traz uma interferência ao valor da proteção à propriedade privada; já $\sim \mathrm{C}$, ao contrário, concretiza o valor da proteção à propriedade privada e traz uma interferência no valor da proteção da liberdade. Abstraindo os dados da situação concreta e utilizando, para resolver o conflito, a mera preponderância ou peso abstrato dos valores mencionados, a escolha deveria recair sobre C. No entanto, pode ocorrer que, na situação concreta, a interferência que $\mathrm{C}$ impõe à propriedade privada é muito mais intensa que a interferência imposta por $\sim \mathrm{C}$ à liberdade. Nessa situação, tais circunstâncias são suficientes para justificar a opção por $\sim \mathrm{C}$, revelando-se a proteção à propriedade, nesse caso e à luz das circunstâncias mencionadas, insista-se, o valor preponderante, isto é, de maior peso específico ou concreto.

Dessa forma, limitações à realização de um valor constitucional qualquer só são lícitas ou constitucionalmente legítimas, quando exigidas pela realização de um outro valor constitucional que se revele concretamente preponderante, o

${ }^{9}$ Com efeito, este consiste em um dos aspectos mais importantes da genial teoria dos direitos fundamentais de Robert Alexy, aspecto este que, todavia, só veio a ficar plenamente esclarecido com a recente elaboração, pelo mestre alemão, de sua "Fórmula do Peso". Tal fórmula, na verdade, consiste numa perfeita estrutura de argumentação, estabelecendo com clareza o que se deve discutir para determinar a preponderância de um princípio ou valor constitucional sobre algum outro, com o qual venha a colidir. Ademais, à luz desta fórmula, permite-se compreender, com clareza solar, que nesta ponderação de valores em conflitos devem ser levadas em consideraçào, sempre $e$ necessariamente, aspectos da realidade concreta, os quais podem, como se vai exemplificar no texto, justificar que um valor de maior relevância, numa perspectiva puramente abstrata, venha a ser sacrificado em nome de outro. Isto é suficiente para tornar inteiramente inadmissível qualquer tentativa, sobretudo por intervenção do legislador, de estabelecer soluções abstratas, válidas para qualquer circunstância, para eventuais conflitos de princípios ou valores constitucionais. Sobre a Fórmula do Peso de Alexy, cf. Alexy $(2002,2003)$.

${ }^{10}$ Sublinhe-se que qualquer conflito entre valores constitucionais só ocorre no plano concreto, uma vez que o conflito de valores no plano abstrato pressupõe a inimaginável situação em que toda e qualquer conduta capaz de realizar um determinado valor seja, igualmente, apta a obstaculizar um outro valor. 
que, como se viu, só pode ser relativo a uma determinada situação concreta. Por isso, sendo a preponderância de um valor sobre outro ou o seu peso concreto com relação a outro valor, uma "grandeza" completamente dependente da situação concreta em que ambos valores entram em colisão, as limitações também o são.

À luz dessas considerações, é possível formular um juízo mais seguro sobre normas que vedam a concessão de providências antecipatórias urgentes contra a Fazenda Pública, em determinados grupos de casos. É amplamente sabido que a Fazenda Pública tem peculiaridades que justificam, em linha de princípio, um tratamento diferenciado. Tais peculiaridades, sobretudo a natureza (pública) dos interesses por ela defendidos e a relevância dos mesmos, podem se manifestar também no contexto em que se decide sobre a concessão ou não de providências urgentes. Isso ocorre, basicamente, pela contribuição que a natureza e a relevância dos interesses defendidos pela Fazenda Pública ao conjunto de valores envolvidos no conflito, sempre presente quando da decisão sobre concessão ou não de providências urgentes, de modo tal a desequilibrar, em favor da Fazenda, o cômputo geral da preponderância relativa de tais valores. Com efeito, pode perfeitamente ocorrer que, mesmo presente o periculum in mora, as mencionadas peculiaridades da Fazenda Pública sejam suficientes para fazer surgir um periculum in mora "inverso", ou seja, que a concessão de providência urgente se revele trazer uma restrição maior a valores constitucionais do que aquela restrição que, com a providência urgente se busca combater.

Nesses casos, são constitucionalmente legítimas restrições à concessão de qualquer providência urgente contra a Administração Pública, e não apenas naqueles grupos referidos pelas sucessivas leis proibitivas. Tais restrições, vale sublinhar, estão latentes no ordenamento jurídico, na própria natureza aberta dos valores constitucionais e do respectivo modo (adequado) de solução de conflitos entre eles. Mesmo onde não existam restrições legais à concessão de providências urgentes, antecipatórias ou conservativas, contra a Administração Pública, ou não, sempre que se verificar situações de periculum in mora inverso, não deve ser concedida providência urgente.

Dessa forma, não se revelam inconstitucionais, para esse tipo de situação, as normas que vedam a concessão de providências urgentes antecipatórias contra o Poder Público. Todavia, tais normas não trazem nenhuma contribuição específica para o ordenamento jurídico, pois apenas tornam explícito algo que já existia, implicitamente, no conjunto dos valores positivados nas normas constitucionais. No entanto, nas hipóteses em que não exista o periculum in mora inverso, ou seja, nas situações em que a máxima coincidência e outros valores que venham a ser beneficiados com a concessão de providência urgente antecipatória se revelem 
mais preponderantes, concretamente, do que aqueles que seriam beneficiados com a denegação de tal providência, nessas situações, portanto, qualquer limitação legal (ou judicial) à sua concessão se caracteriza como uma frontal e inaceitável violação da Constituição. Dito de outro modo, se é certo que não se pode qualificar como inconstitucional, em todas as circunstâncias, norma proibitiva de providência antecipatória urgente contra o Poder Público, não menos certo é também não se pode qualificar, em todas as circunstâncias, tal norma como constitucional.

\section{A DISTINÇÃO ENTRE NORMA E TEXTO E AS DUAS DECISÕES-NORMAS QUE SE PODE EXTRAIR DO TEXTO ATRAVÉS DO QUAL O STF VEICULOU DECISÃO LIMINAR NA ADC N. 4}

Resta, no tanto, saber como se acomodam - se é que se acomodam - tais conclusões à circunstância de que as normas proibitivas de concessão de providências antecipatórias urgentes contra o Poder Público tenham sido consideradas, ao menos liminarmente, como constitucionais, pelo Supremo Tribunal Federal. Para elaborar uma análise mais aprofundada do caso, é de extrema relevância advertir que a distinção entre norma e texto legislativo, que já está se tornando bastante conhecida, na doutrina brasileira, aplica-se a todos os atos jurídicos e não apenas aos atos normativos. ${ }^{11}$ Com efeito, também os contratos, os atos administrativos e os atos processuais são "entidades abstratas" - como a velha e mais tradicional ciência jurídica sempre percebeu, intuitivamente, identificando como elemento essencial deles a "declaração de vontade" - da ordem daquilo que se pode chamar de sentido ou significado ("meaning content"). Dessa forma, também estes atos jurídicos, quando praticados através do uso de expressões lingüísticas, como sói ocorrer, não se confundem com essas mesmas expressões lingüísticas. Tanto é que, traduzindo os termos de um instrumento de contrato para outra língua, não se tem dois contratos diferentes, mas um só, veiculados por dois conjuntos distintos de expressões lingüísticas, ou textos.

À luz destas idéias, há de se distinguir, portanto, a decisão (judicial)-norma ou decisão-ato, da decisão-texto, por meio da qual a primeira é veiculada, sem que ambas se confundam. Dessa forma, a decisão do STF, ou melhor, o seu texto,

${ }^{11}$ Sobre essa peculiar ontologia da norma, baseada na distinção entre norma e texto, cf. Guerra (2004) e o artigo "Norma, texto e a metáfora da moldura em Kelsen" (Revista dos Tribunais, no prelo); sobre a distinção entre norma e texto cf. também, Guastini (2001, p. 13-13). 
admite duas leituras, vale dizer, do texto proferido pelo STF pode-se extrair, como seu significado, duas decisões distintas. Uma delas é a de que a lei que veda a concessão de providência antecipatória urgente contra o Poder Público é considerada constitucional em geral, não ficando excluída a possibilidade de deixar de ser aplicada, quando restar evidenciada, no caso concreto, uma maior preponderância dos valores constitucionais realizados com a concessão da providência. Nesse caso, a decisão do STF se acomoda, integralmente, às considerações formuladas no presente estudo.

A outra leitura é a de que em nenhuma circunstância a lei considerada liminarmente constitucional poderá deixar de ser aplicada. Nesse caso, pelos argumentos já expostos, a decisão do STF se revela uma frontal violação à Constituição, uma frontal desconsideração da natureza das normas constitucionais.

\section{REFERÊNCIAS}

ALEXY, Robert. Postcript. In: . A Theory of Constitutional Rights. Trans. Julian Rivers. Oxford: Oxford University Press, 2002.

On balancing and subsumption: a structered comparision. Ratio Juris, v. 16, n.4, p. 433-449, 2003.

ALVIM WAMBIER, Teresa Arruda (Coord.). Aspectos polêmicos da antecipação de tutela. São Paulo: Editora Revista dos Tribunais, 1997.

. Os Agravos no CPC Brasileiro. 4. ed. São Paulo: Revista dos Tribunais, 2006.

BARBOSA MOREIRA, José Carlos. Tendências na execução de sentenças e ordens judiciais. In Temas de Direito Processual - quarta série. São Paulo: Saraiva, 1989.

BEDAQUE. José Roberto dos Santos. Tutela cautelar e tutela antecipada: tutelas sumárias de urgência (tentativa de sistematização). 2.ed. São Paulo: Malheiros, 2001.

BENUCCI. Renato Luís. Antecipação da tutela em face da Fazenda Pública. São Paulo: Dialética, 2001.

BUENO, Cássio Scarpinella. Tutela antecipada. São Paulo: Saraiva, 2004.

.O poder público em juízo. São Paulo: Max Limonad, 2000.

BUENO, Cássio Scarpinella; SUNDFELD, Carlos Ari (Coord.). Direito processual público: a Fazenda Pública em juízo. São Paulo: Malheiros, 2000. 
DANTAS, Francisco Wildo Lacerda. Execuções contra a Fazenda Pública: regime do precatório. Brasília: Brasília Jurídica, 1999.

FEDERIGHI, Wanderley José. A execução contra a Fazenda Pública. São Paulo: Saraiva, 1996.

FRIAS, Jorge Eustácio da Silva. Tutela antecipada em face da Fazenda Pública. Revista dos Tribunais, São Paulo, v. 728, p. 60-79, jun. 1996.

GUASTINI, Riccardo. Il Diritto come Linguaggio - Lezioni. Torino: G. Giappichelli Editore, 2001.

GUERRA, Marcelo Lima. Direitos fundamentais e a proteção do credor na execução civil. São Paulo: Editora Revista dos Tribunais, 2003.

. Estudos sobre o Processo Cautelar. São Paulo: Malheiros, 1997. . Execução Indireta. São Paulo: Editora Revista dos Tribunais, 1998.

. Norma: uma entidade semântica. In: MACEDO, Dimas (Org.). Filosofia e Constituição - Estudos em homenagem a Raimundo Bezerra Falcão. Rio de Janeiro: Letra Legal, 2004.

. Norma, texto e a metáfora da moldura em Kelsen. Revista dos Tribunais, São Paulo. (no prelo)

GRECO FILHO, Vicente. Da execução contra a Fazenda Pública. São Paulo: Saraiva, 1986.

HESSE, Konrad. Elementos de direito constitucional da República Federal da Alemanha. tradução de Luís Afonso Heck. Porto Alegre: Sérgio Fabris Editor, 1998.

MaCCORMICK, Neil. Legal Reasoning and Legal Theory. Oxford: Clarendon Press, 1978.

ROCHA SOBRINHO, Délio José. Prerrogativas da Fazenda Pública em juízo. Porto Alegre, Fabris, 1999.

SHIMURA, Sérgio, ALVIM WAMBIER, Teresa Arruda (Coord.). Processo de execução. São Paulo: Editora Revista dos Tribunais, 2001.

SILVA, Américo Luís Martins da. Do precatório-requisitório na execução contra a Fazenda Pública. Rio de Janeiro: Lumen Juris, 1996.

SILVA, Ricardo Perlingeiro Mendes da. Execução contra a Fazenda Pública. São Paulo: Malheiros, 1999. 
SOUZA, Otávio Augusto Reis de. A tutela antecipada e as pessoas jurídicas de direito público. São Paulo: LTr, 2000.

SPAAK, Torben. The Concept of legal competence: an essay in conceptual analysis. Trad. Robert Carroll. Aldershot: Dartmouth, 1994.

VENTURI, Elton. Suspensão de liminares e sentenças contrárias ao Poder Público. São Paulo: Editora Revista dos Tribunais, 2005.

VIANA, Juvêncio Vasconcelos. Efetividade do processo em face da Fazenda Pública. São Paulo: Dialética, 2003. . Execução contra a Fazenda Pública. São Paulo: Dialética, 1998.

VILELA, Gilberto Etchaluz. A suspensão das liminares e sentenças contra o poder público. Porto Alegre: Síntese, 1998.

WAMBIER, Luiz Rodrigues. Antecipação de tutela em face da Fazenda Pública. Revista de Processo, São Paulo, ano 22, n. 87, p. 32-36, jul./set. 1997. 